\section{De revisores, anonimatos, cobardía y mala educación}

\section{About referees, anonymous, cowardice and bad education}

Nuestra revista tiene la sana costumbre de remitir a los revisores los trabajos excluyendo la identidad de los autores y otros aspectos que no tienen porqué ser tenidos en cuenta en una valoración científica. No ocurre lo mismo en la mayoría de las revistas oftalmológicas, en las que el revisor recibe toda esta información adicional.

Es decir, que se mantiene el anonimato del evaluador para que se sienta libre de expresar lo que piensa (cuestión que debería hacer en cualquier caso), y se le ayuda a liberar sobre el revisado cualquier carga emotiva o prejuicio que pueda acumular, sin ningún peligro.

Mi opinión personal es que el anonimato es solo una ventaja para los cobardes. Mis mejores amigos en la Oftalmología española son personas con las que me paso la vida discutiendo y discrepando. Simplemente nos sabemos impulsados por el mismo afán de descubrir una verdad científica, y aunque somos apasionados en nuestros argumentos, sabemos deslindar la amistad de la pasión por el trabajo.

Han sido excepcionales las ocasiones en que algún colega se ha atrevido, en público, a hacerme las objeciones del mal talante y falta de cortesía, que frecuentemente encuentro entre los revisores anónimos de mis trabajos. Y ello pese a que conocen que mis limitaciones de idioma no me pondrían fácil responder. Sin embargo, he visto, con relativa frecuencia, ensañarse en público con colegas japoneses, ante la convicción de que las posibilidades de recibir un revolcón como respuesta eran absolutamente nulas.

Los editores deberían meditar sobre el resultado de esta costumbre, o al menos corregir los abusos, excluyendo del grupo de evaluadores a aquellos que no sepan mantener la imparcialidad y la compostura.

Es raro el trabajo que remito que no me termina produciendo un disgusto en este sentido. No suele ser el caso de nuestra revista, ni de otras de la Europa continental, pero en el resto de los casos el destino parece ser inevitablemente el mismo.

$\mathrm{He}$ de reconocer que en algunas ocasiones los editores han atendido a mis protestas. En algunos casos corrigiendo errores y, en otros curiosamente ofreciéndome en bandeja la venganza. La única vez que actué como revisor de una de las revistas de mayor impacto de nuestra especialidad, fue para valorar el trabajo de una persona que sin duda fue el revisor de uno de mis trabajos, sobre el que había planteado quejas al Editor. ¡Curiosa forma de mantener el equilibrio, muy propia del Lejano Oeste y de la política al uso!

Otras veces verdaderamente he observado un mayor equilibrio en el Editor. Recientemente un revisor argumentaba sobre uno de mis trabajos, entre otras lindezas, lo siguiente: «los autores deberían esforzarse más en corregir el manuscrito que en refutar los comentarios de los revisores». Respondí que la frase no era un modelo de cortesía y parecía indicar que el revisor se consideraba dotado de un nivel intelectual muy superior al nuestro. Como consecuencia el editor cambió de revisor y el trabajo parece en vías de aceptación con ligeras modificaciones. ¡Chapó!

Otro bello ejemplo de mala educación lo recibí hace pocos días. Aunque la revista no lo exigía, incluí una nota en el trabajo indicando que tenía intereses comerciales en la metodología del trabajo. El trabajo fue rechazado sin derecho a réplica, con una serie de comentarios que demostraban una profunda ignorancia de los revisores sobre el tema y este curioso comentario: «Dado que el primer autor reconoce tener interés económico en la técnica utilizada, toda la comunidad científica deberá exigirle más pruebas de las habituales antes de aceptar el tono del manuscrito». Es decir que si usted es futbolista, cantante de copla o cirujano, puede hacerse rico ante el aplauso de la concurrencia, pero si usted en vez de ser favorecido por la naturaleza con habilidades motoras o laríngeas, intenta utilizar la inteligencia para ganarse la vida, lo más probable es que será usted envidiado, ofendido y vilipendiado. No recuerdo ningún trabajo quirúrgico (especialmente sobre Lasik y cirugía de cristalino transparente) en el que el cirujano describa cuántos euros ha ganado en el transcurso de las experiencias que describe o defiende.

Capítulo aparte merece el tema del idioma. Reconozco que mi habilidad en este aspecto es escasa, y que me introduje tardíamente con el inglés. En mi tierra dicen que «loro viejo no aprende conversación». Para compensar este déficit mi hija, que estudió su licenciatura de Optometría en Londres me ayuda a preparar los trabajos, y finalmente los corrige un profesor nativo de inglés para médicos, altamente cualificado. Sin embargo, todos 
mis revisores encuentran errores fundamentales en el lenguaje. Posiblemente porque son de Kansas y mi traductor es británico-sudafricano, pero se cuidan mucho de no ayudarte a corregir tus supuestos errores. Me contaba un amigo de Miami de un norte-americano de la zona centro (que no solamente americano), que le preguntaba a un londinense dónde había aprendido a hablar inglés.

Cuando los invitamos a España, les ponemos un traductor simultáneo y nos desvivimos por comprenderlos y, si quisiesen publicar en castellano encontrarían, sin duda, decenas de voluntarios para traducirles. Indudablemente entendemos la cortesía de otra manera. Yo he optado por contestar a los revisores que cualquier sugerencia para mejorar el estilo, procedente de una persona de su elevado conocimiento del inglés será agradecida. Sin embargo, no suelen captar la idea. ¡Que le vamos a hacer!

Tenerife. Europa Africana.... por el momento (antes Atlántica).

González de la Rosa M

Doctor en Medicina. Sta. Cruz de Tenerife. España E-mail: mgdelarosa@jet.es 